\title{
Faktor-Faktor yang Mempengaruhi Sikap Remaja Putri tentang Flour Albus di SMP Negeri 2 Trucuk Kabupaten Klaten
}

\author{
Susiana Sariyati ${ }^{1}$ \\ ${ }^{1}$ Sekolah Tinggi IImu Kesehatan Alma Ata Yogyakarta \\ Jalan Ringroad Barat Daya No 1 Tamantirto, Kasihan, Bantul, Yogyakarta
}

\begin{abstract}
Abstrak
Flour Albus adalah keluarnya cairan yang berlebihan yang menyebabkan seorang remaja putri sering kali mengganti pakaian dalam atau menggunakan pembalut. Minimnya pengetahuan remaja putri tentang flour albus dapat berdampak pada sikap remaja putri yang kurang perhatian (negatif) dengan flour albus yang di alaminya. Tujuan penelitian ini adalah untuk mengetahui faktor-faktor yang mempengaruhi sikap remaja putri dengan flour albus di SMP Negeri 2 Trucuk Kabupaten Klaten. Desain penelitian menggunakan cross sectional. Populasi dalam penelitian ini adalah seluruh remaja putri kelas IX dengan jumlah 120 siswi, sampel penelitian ini adalah remaja putri kelas IX yang sudah menstruasi yaitu berjumlah 92 siswi dengan teknik pengambilan simple random sampling. Hasil penelitian sebagian besar remaja putri mempunyai pengetahuan yang baik. Faktor yang paling berhubungan dengan sikap adalah pengetahuan yang didukung oleh faktor informasi dan pengalaman. Kesimpulan dari penelitian terdapat Hubungan positif dan signifikan antara pengetahuan dengan sikap, terdapat Hubungan positif dan signifikan antara pengalaman dengan sikap, terdapat Hubungan positif dan signifikan antara sumber informasi dengan sikap.
\end{abstract}

Kata Kunci: keputihan, pengetahuan, pengalaman, sumber informasi, sikap

\section{Factors That Affects Adolescent Girls Attitude about Flour Albus in Trucuk 2 Junior High Schools District Klaten}

\begin{abstract}
Flour albus is a discharge excessive that causes an adolescent girls often replace the underwear or using a bandage. Less of knowledge about flour albus may impact on adolescent girls negative attitude or less attention about flour albus. The purpose of this study was to find the factors that affected adolescent girls attitude about flour albus in Trucuk 2 Junior High School District Klaten. Study design used in this study was cross sectional. The population of $9^{\text {th }}$ grade adolescent girls were 120 female students. The samples of this study were 92 adolescent girls that already menstruation. Samples were selected by simple random sampling technique. The results showed that most of adolescent girls had a good knowledge. The factors that most affected adolescent girls attitude was knowledge supported by information and experience. In conclusion, there was a significant relationship between knowledge and attitude, there was a significant relationship between experience and attitude, there was a significant relationship between source of information and attitude.
\end{abstract}

Keywords: attitudes, experience, knowledge, resources, whitish

Info Artikel:

Artikel dikirim pada 12 Januari 2014

Artikel diterima pada 12 Januari 2014 


\section{PENDAHULUAN}

Kesehatan reproduksi menjadi masalah yang serius sepanjang daur kehidupan. Pemerintah tetap melihat penanganan persoalan kesehatan reproduksi remaja dalam konteks perundang - undangan yang berlaku dan kondisi sosial budaya masyarakat Indonesia. Pemerintah sangat mendukung pemberian informasi, konseling dan pelayanan kesehatan reproduksi seluas-luasnya kepada para remaja sebagai bagian dari hak reproduksi mereka. Sasaran program kesehatan reproduksi adalah seluruh remaja dan keluarganya supaya memiliki pengetahuan, kesadaran, sikap dan perilaku kesehatan reproduksi yang bertanggung jawab, sehingga siap menjadi keluarga yang berkualitas tahun 2015(1).

Masalah keputihan merupakan masalah yang sejak lama yang menjadi persoalan bagi kaum wanita, tidak banyak wanita yang mengetahui tentang keputihan. Padahal keputihan tidak bisa dianggap ringan, karena sangat fatal bila tidak cepat segera ditangani. Tidak hanya bisa mengakibatkan kemandulan tetapi keputihan juga merupakan gejala awal dari kanker leher rahim, yang dapat mengakibatkan kematian, keputihan juga dapat menekan kejiwaan seseorang karena keputihan cenderung kambuh dan timbul kembali sehingga dapat mempengaruhi seseorang baik secara fisiologi maupun psikologis(2).

Menurut BKKBN di Indonesia sebanyak $75 \%$ wanita pernah mengalami Keputihan minimal satu kali dalam hidupnya dan $45 \%$ diantaranya bisa mengalami keputihan sebanyak dua kali atau lebih(3). Banyak wanita di Indonesia tidak mengetahui tentang keputihan sehingga mereka menganggap keputihan sebagai hal yang umum biasa terjadi, disamping itu rasa malu ketika mengalami keputihan kerap membuat wanita enggan berkonsultasi ke dokter(4).

Remaja merupakan salah satu bagian dari populasi yang beresiko mengalami keputihan yang memerlukan perhatian khusus. Akibat keputihan ini sangat fatal jika terlambat di tangani. Tidak hanya mengakibatkan kemandulan dan hamil di luar kandungan tetapi juga merupakan gejala awal dari kanker leher rahim(5).

Daerah kewanitaan jika tidak di bersihkan secara benar mempunyai peluang 3,5 kali terjadi keputihan dibandingkan pada remaja putri yang membersihkan daerah kewanitaan dengan benar. Remaja yang tidak baik membersihkan daerah kewanitaan sebanyak 42 orang (84\%) mengalami keputihan(6).

Sangat penting bagi remaja putri mendapat pengetahuan kesehatan reproduksi khususnya keputihan agar mereka mengetahui bagaimana seharusnya mereka bersikap menghadapi keputihan yang nantinya akan berhubungan dengan keputihan yang dialaminya(7).

Pada remaja yang kurang pengetahuan dan informasi tentang kebersihan alat genetalia akan berdampak pula pada perilaku remaja dalam menjaga kebersihan alat genetalianya. Karena pengetahuan dan perilaku perawatan yang baik merupakan faktor penentu dalam memelihara kebersihan alat genetalia(8).

Penelitian ini bertujuan untuk mengetahui faktor-faktor yang mempengaruhi sikap remaja putri tentang flour albus di SMP Negeri 2 Trucuk Klaten. Faktor tersebut meliputi pengetahuan, pengalaman, sumber informasi.

\section{BAHAN DAN METODE}

Penelitian ini menggunakan desain penelitian cross sectional yang di laksanakan di SMP Negeri 2 Trucuk Klaten pada bulan Agustus sampai November 2012. Populasi dalam penelitian ini adalah seluruh remaja putri kelas IX dengan jumlah 120 siswi, sampel penelitian ini adalah remaja putri kelas IX yang sudah menstruasi yaitu berjumlah 92 siswi dengan teknik pengambilan simple random sampling. Data dikumpulkan dengan menggunakan angket dengan kuesioner yang dibagikan kepada responden untuk mendapatkan data mengenai pengetahuan, pengalaman, sumber informasi dan sikap responden. Analisis data menggunakan analisis univariat untuk menggambarkan distribusi frekuensi dan proporsi masing-masing variabel. Analisis bivariat untuk melihat hubungan variabel independen dengan variabel dependen dengan menggunakan uji chi-square. Kemaknaan diukur dengan menggunakan derajat kemaknaan (nilai-p) $5 \%$.

\section{HASIL DAN BAHASAN}

Hasil penelitian ini dapat dilihat pada Tabel 1 dari berbagai kategori dapat diketahui bahwa pengetahuan remaja putri pada kategori tinggi sebanyak $64(69,6 \%)$ siswi, pengalaman remaja putri yang sudah pernah mengalami flour albus sebanyak $83(90,2 \%)$ siswi, sumber informasi remaja putri yang sudah pernah mengalami flour albus sebanyak 60 $(65,2 \%)$ siswi, dan remaja putri dengan sikap positif tentang flour albus sebanyak 59 (64,1\%) siswi.

Hasil hitung analisis bivariat antar variabel dapat dilihat pada Tabel 2. Berdasarkan hasil hitung diketahui bahwa $\chi_{\text {hitung }}^{2} 28,867$ lebih besar dari $\chi_{\text {tabel }}^{2} 5,591$ dan $p$-value 0,000 lebih kecil dari 0,05 pada taraf signifikan $5 \%$, jadi terdapat hubungan yang positif dan signifikan antara pengetahuan dengan sikap remaja putri tentang 
Tabel 1. Distribusi Frekuensi Kategori Remaja Putri SMP Negeri 2 Trucuk Klaten

\begin{tabular}{lcc}
\hline Kategori & $\mathbf{f}$ & $\mathbf{\%}$ \\
\hline Pengetahuan & & \\
Tinggi & 64 & 69,6 \\
Cukup & 22 & 23,9 \\
$\quad$ Rendah & 6 & 6,5 \\
Pengalaman & & \\
$\quad$ Pernah & 83 & 90,2 \\
$\quad$ Tidak Pernah & 9 & 9,8 \\
Informasi & & \\
$\quad$ Pernah & 60 & 65,2 \\
$\quad$ Tidak Pernah & 35 & 34,8 \\
Sikap & & \\
$\quad$ Positif & 59 & 64,1 \\
$\quad$ Negatif & 33 & 35,9 \\
Jumlah & 92 & 100 \\
\hline
\end{tabular}

Sumber: Data Primer

flour albus di SMP Negeri 2 Trucuk Kabupaten Klaten dengan koefisien contingency sebesar 0,489 yang berarti tingkat keeratan hubungan sedang.

Hasil analisis bivariat hubungan pengalaman dengan sikap diketahui bahwa $\chi_{\text {hitung }}^{2} 17,836$ lebih besar dari $\chi_{\text {tabel }}^{2} 3,481$ dan $p$-value 0,000 lebih kecil dari 0,05 pada taraf signifikan $5 \%$, jadi terdapat hubungan yang positif dan signifikan pengalaman dengan sikap remaja putri tentang flour albus di SMP Negeri 2 Trucuk Kabupaten Klaten dengan Koefisien contingency sebesar 0,403 yang berarti tingkat keeratan hubungan sedang.

Hasil analisis bivariat hubungan sumber informasi dengan sikap diketahui bahwa $\chi_{\text {hitung }}^{2} 18,886$ lebih besar dari $\chi_{\text {tabel }}^{2} 3,481$ dan $p$-value 0,000 lebih kecil dari 0,05 pada taraf signifikan $5 \%$, jadi terdapat hubungan yang positif dan signifikan pengalaman dengan sikap remaja putri tentang flour albus di SMP Negeri 2 Trucuk Kabupaten Klaten dengan koefisien contingency sebesar 0,413 yang berarti tingkat keeratan hubungan sedang.
Berdasarkan Tabel 3 didapat hasil analisis multivariat hubungan antara pengetahuan, pengalaman, sumber informasi dengan sikap adalah variabel sumber informasi dengan $p$-value 0,000 dan lebih kecil dari 0,05 pada taraf signifikan $5 \%$.

Penelitian ini menunjukan sebagian besar remaja putri dengan pengetahuan baik mempunyai sikap yang positif sebanyak $52(56,5 \%)$ sedangkan remaja putri dengan pengetahuan kurang akan mempunyai sikap yang negatif sebanyak $6(6,5 \%)$.

Pada remaja yang kurang pengetahuan dan informasi tentang kesehatan reproduksi terutama keputihan akan berdampak pula pada perilaku remaja dalam menjaga kebersihan alat genitalianya. Karena pengetahuan dan perilaku perawatan yang baik merupakan faktor penentu dalam memelihara kebersihan alat genitalia(3).

Kurangnya pengetahuan dan informasi mengenai cara perawatan daerah kewanitaan yang benar dan ketidakpahaman remaja putri mengenai cara perawatan yang baik dan benar sehingga dapat menyebabkan terjadinya keputihan(9).

Pengetahuan remaja putri tentang perawatan daerah kewanitaan rendah disebabkan karena rendahnya kesadaran tentang pentingnya menjaga kebersihan organ reproduksi dan berpengaruh pada perilaku remaja yang akibatnya dapat terjadi masalah pada daerah kewanitaan(10).

Pengetahuan merupakan salah satu dari ketiga komponen pembentuk sikap yaitu komponen kognitif. Dalam teori Rosenberg, pengetahuan dan sikap berhubungan secara konsisten. Bila komponen kognitif (pengetahuan) berubah, maka akan diikuti perubahan sikap. Berdasarkan teori tersebut dapat disimpulkan bahwa pengetahuan seseorang seharusnya berhubungan dengan sikapnya. Berdasarkan teori tersebut dapat disimpulkan bahwa pengetahuan seseorang sudah seharusnya berhubungan dengan sikapnya(11).

Tabel 2. Analisis Bivariat antar Variabel

\begin{tabular}{lccccc}
\hline Variabel Independen & df & $\chi_{\text {hitung }}^{2}$ & $\chi_{\text {tabel }}^{2}$ & p-value & koefisien \\
\hline Pengetahuan & 2 & 28,867 & 5,591 & 0,000 & 0,489 \\
Pengalaman & 1 & 17,836 & 3,481 & 0,000 & 0,403 \\
Sumber Informasi & 1 & 18,886 & 3,481 & 0,000 & 0,413 \\
\hline
\end{tabular}

Sumber: Data Primer

Tabel 3. Analisis Multivariat

\begin{tabular}{lccccc}
\hline \multicolumn{1}{c}{ Variabel Independen } & B & S.E & Wald & df & p-value \\
\hline Pengetahuan & 3,753 & 1,113 & 11,373 & 1 & 0,001 \\
Pengalaman & 3,950 & 1,676 & 5,551 & 1 & 0,018 \\
Sumber Informasi Constant & 4,904 & 1,335 & 13,504 & 1 & 0,000 \\
& $-11,481$ & 3,126 & 13,490 & 1 & 0,000 \\
\hline
\end{tabular}

Sumber: Data Primer 
Selain faktor tersebut bahwa orang tua merupakan faktor yang mempengaruhi pengetahuan remaja, karena peran orang tua dalam mendidik anak sangat menentukan arah pengetahuan anak, disamping itu perkembangan teknologi dan banyaknya media massa dapat pula mempengaruhi tingkat pengetahuan masyarakat. Kebiasaan dan tradisi yang dilakukan baik atau buruk dengan demikian seseorang akan bertambah tingkat pengetahuannya, pengetahuan juga dapat membentuk keyakinan tertentu sehingga seseorang berperilaku sesuai keyakinan tersebut. Orang yang telah faham dengan objek atau materi dapat menjelaskan, menyebutkan contoh menyimpulkan, meramalkan, dan sebagainya dengan objek yang dipelajari(8).

Dalam teoriWHO, dijelaskan bahwa pengetahuan dipengaruhi oleh pengalaman seseorang, faktorfaktor luar orang tersebut (lingkungan), baik fisik maupun non fisik dan sosial budaya yang kemudian pengalaman tersebut diketahui, dipersepsikan, diyakini sehingga menimbulkan motivasi, niat untuk bertindak dan pada akhirnya terjadi perwujudan niat berupa perilaku(11).

Untuk membentuk perilaku yang baik pada remaja putri harus menambah pengetahuannya dengan cara remaja putri menerima input dan untuk itu seseorang harus mempertimbangkan logika dalam pengambilan keputusan untuk berperilaku yang baik. Seorang remaja yang telah memiliki pengetahuan memadai tentang kesehatan reproduksi yang dalam penelitian ini adalah mengenai keputihan diharapkan dapat menerapkan pengetahuannya dalam berperilaku sehingga dapat hidup lebih sehat yang nantinya dapat mengahasilkan generasigenerasi penerus bangsa(6).

Pengalaman sangatlah berhubungan dengan sikap seseorang, semakin seseorang pernah mengalami sesuatu atau berpengalaman maka dia akan mempunyai sikap yang positif. Pengalaman merupakan sumber pengetahuan dan cara untuk memperoleh kebenaran pengetahuan. Oleh sebab itu pengalaman pribadi pun dapat digunakan sebagai upaya untuk memperoleh pengetahuan. Hal ini dilakukan dengan cara mengulang kembali pengalaman yang diperoleh dalam memecahkan permasalahan yang dihadapi pada masa lalu(12).

Tidak adanya pengalaman sama sekali dengan suatu objek psikologis cenderung akan membentuk sikap negatif dengan objek tersebut. Sikap akan lebih mudah terbentuk apabila pengalaman pribadi tersebut terjadi dalam situasi yang melibatkan emosi, penghayatan akan pengalaman lebih mendalam dan lebih lama berbekas(13).
Setelah mengalami perubahan pisik, remaja akan mengalami perubahan emosional, pikiran, perasaan, pergaulan, dan tanggung jawab yang dihadapi yang akan tercermin dalam sikap dan tingkah laku. Maka seorang remaja harus mendapatkan informasi yang benar terutama pengetahuan tentang keputihan(14).

Dalam penelitian ini sebagian besar responden mendapatkan sumber informasi dari orang tua. Dimana sikap sangat dipengaruhi oleh orang lain yang dianggap penting, salah satunya adalah orang tua mereka. Para responden mengatakan bahwa alasan mereka mengganti pakaian dalam karena dianjurkan oleh orang tua mereka, misalnya dalam mengobati keputihan dengan daun sirih karena orang tua mereka mengatakan bahwa daun sirih dapat mengobati keputihan.

Masalah kesehatan reproduksi paling banyak dialami remaja putri karena kurang tersedianya akses untuk mencari informasi tentang kesehatan reproduksi yang benar. Pengetahuan dan kesadaran remaja tentang reproduksi terutama keputihan sangat rendah(15).

Orang tua perlu memahami kondisi anak remajanya yang sedang mengalami perubahanperubahan pada dirinya, yang menyangkut proses reproduksi. Orang tua harus mempunyai kemampuan memberikan pengetahuan kesehatan reproduksi kepada anak remajanya, agar memilki informasi proses reproduksi yang benar. Dengan informasi yang benar, diharapkan remaja memiliki sikap dan tingkah laku yang bertanggung jawab khususnya mengenai proses reproduksi(16).

Keterbatasan pengetahuan dan informasi tentang kesehatan reproduksi orang tua juga dapat menjadi pencetus perilaku atau kebiasaan tidak sehat pada remaja. Hal ini berawal dari sikap orang tua yang menabukan pertanyaan remaja tentang fungsi dan proses reproduksi, serta penyebab rangsangan seksualitas. Orang tua cenderung risih dan tidak mampu memberikan informasi yang memadai mengenai alat reproduksi dan proses reproduksi itu. Tiadanya informasi dari orang tua membuat remaja mengalami kebingungan akan fungsi dan proses reproduksinya(17).

Selain orang tua media massa sebagai sumber informasi. Berbagai bentuk media massa seperti televisi, radio, surat kabar, majalah dll, mempunyai Hubungan besar dalam pembentukan opini dan kepercayaan orang. Penyampaian informasi sebagai tugas pokoknya. Media massa membawa pula pesanpesan yang berisi sugesti yang dapat mengarahkan opini seseorang. Adanya informasi baru mengenai sesuatu hal memberikan landasan kognitif baru bagi terbentuknya sikap dengan hal tersebut(18). 


\section{SIMPULAN DAN SARAN}

Berdasarkan hasil penelitian dapat disimpulkan bahwa terdapat hubungan positif dan signifikan antara pengetahuan dengan sikap sebesar 0,000 pada taraf signifikan 0,05 dengan koefisien contingency sebesar 0,489 yang berarti tingkat keeratan dalam kategori sedang, terdapat hubungan positif dan signifikan antara pengalaman dengan sikap sebesar 0,000 pada taraf signifikan 0,05 dengan koefisien contingency sebesar 0,403 yang berarti tingkat keeratan dalam kategori sedang, terdapat hubungan positif dan signifikan antara sumber informasi dengan sikap remaja putri tentang flour albus di SMP Negeri 2 Trucuk Kabupaten Klaten sebesar 0,000 pada taraf signifikan 0,05 dengan koefisien contingency sebesar 0,413 yang berarti tingkat keeratan dalam kategori sedang, dan variabel yang paling berhubungan dengan sikap adalah sumber informasi dengan $p$-value sebesar 0,000 . Saran bagi remaja agar lebih meningkatkan pengetahuan tentang flour albus.

\section{RUJUKAN}

1. Astuti. Hubungan Perilaku Vulva Hygiene Dengan Kejadian Keputihan Pada Remaja Putri Kelas X Di SMUN 2 Ungaran Semarang. Jurnal Kebidanan Dan Keperawatan. 2008;4(2):59-65.

2. Solikhah R. Hubungan Tingkat Pengetahuan Tentang Keputihan Dengan Perilaku Remaja Putri Dalam Menjaga Kebersihan Diri Di Desa Bandung Kecamatan Kebumen Kabupaten Kebumen. Jurnal IImiah Kesehatan Keperawatan. 2010; 6(2).

3. Nanlessy. Hubungan Antara Pengetahuan Dan Perilaku Remaja Puteri Dalam Menjaga Kebersihan Alat Genitalia Dengan Kejadian Keputihan di SMA Negeri 2 Pineleng . ejournal Keperawatan (e-Kp). 2013;I(1).

4. Mariana. Keputihan (Fluor Albus) Pada Wanita. Jurnal Al 'Ulum. 2012;51(1):41-46.

5. Prasetyowati. Hubungan Personal Hygiene Dengan Kejadian Keputihan Pada Siswi SMU Muhamadiyah Metro. Jurnal Kesehatan Metro Sai Wawai. 2009;11(2).

6. Johar W. Persepsi Dan Upaya Pencegahan Keputihan Pada Remaja Putri Di Sma Muhammadiyah 1 Semarang. Universitas
Muhammadiyah Semarang Indonesia. Jurnal Keperawatan Maternitas. 2013;I(1):37-45.

7. Sitompul. Pengetahuan dan Sikap Remaja Putri Tentang Keputihan di SMU Negeri 16 Medan. Universitas Sumatera Utara; 2010.

8. Notoatmodjo. IImu Kesehatan Masyarakat. Jakarta: Rineka Cipta; 2003.

9. Setyadi. Faktor-Faktor Yang MemHubungani Kejadian Flour Albus Pada Remaja Putri di SMKN 3 Sukabumi Periode 2011/2012. Jurnal Pendidikan Bidan (The Journal of Midwifery Education) ISSN:2089-2225; 2012.

10. Indrawati Koes. Upaya Meningkatkan Pengetahuan Tentang Kebersihan Organ Reproduksi Siswi Kelas VIII SMPN 10 Surabaya Melalui Metode Tutor Sebaya. E-Jurnal Dinas Pendidikan Kota Surabaya. 2012;5(1).

11. Setiana. Pengetahuan, sikap dan Praktik Mahasiswa Fakultas Kedokteran Dengan Pencegahan Infeksi. Universitas Diponegoro Semarang; 2011.

12. Cahyo. Hubungan Antara Tingkat Pengetahuan, Sikap Dan Ketersediaan Sumber Dengan Perilaku Remaja Putri Dalam Menjaga Kebersihan Organ Genitalia Untuk Mencegah Keputihan di Madrasah Aliyah Negeri 2 Pati; 2011.

13. Rahayuningsih. Psikologi Umum 2; 2008.

14. Wilopo. Remaja Mengenali Dirinya. Jakarta: BKKBN; 2001.

15. Tapparan. Gambaran Perilaku Kebersihan Organ Genetalia Eksterna Siswa Kelas X Sekolah Menengah Atas Negeri 1 Kawangkoan. Jurnal Kedokteran Komunitas Dan Tropik. 2013;I(1).

16. Kurniawan. Faktor-Faktor Yang Berhubungan dengan Praktek Kesehatan Reproduksi Remaja di SMA Negeri 1 Purbalingga Kabupaten Purbalingga. Universitas Diponegoro Semarang; 2008.

17. Winanti. Problematika Remaja Akibat Kurangnya Informasi Kesehatan Reproduksi [internet]. 2012 [cited 2013 Juli 24]. Available from: http:// www.esaunggul .ac.id/article/problematikaremaja-akibatkurangnya-informasi-kesehatanreproduks $\mathrm{i} /$.

18. Kusumastuti. Hubungan Antara Pengetahuan Dengan Sikap Seksual Pranikah Remaja. Universitas Sebelas Maret Surakarta; 2010. 